\title{
A formação de professores em artigos da revista Ciência $\&$ Educação (1998-2014): uma revisão cienciométrica
}

\author{
Teachers" education in articles of the "Ciência \& Educação" \\ journal (1998-2014): a scientometric review
}

Júlio César Castilho Razera ${ }^{1}$

\begin{abstract}
Resumo: A formação de professores aparece em discussões frequentes na área de Educação em Ciências. Encontramos trabalhos diversos em eventos, livros e periódicos, que corroboram a amplitude e relevância desse tema na área. No entanto, ainda há uma lacuna que poderia expor indicadores contributivos e complementares sobre o atual estado de conhecimento dos trabalhos que trazem o assunto em suas abordagens. Com o propósito de preencher parte dessa lacuna, realizamos uma pesquisa cujo objetivo foi traçar um perfil cienciométrico dos artigos sobre formação de professores publicados na revista Ciência \& Educação. De 579 artigos publicados no período de 1998 a 2014, analisamos 345 artigos com descritores referentes à formação de professores. Dirigimos atenção especial a indicadores de autoria, produção, conteúdo e bibliografia. O conjunto de resultados expõe um panorama quantitativo que amplia nossos conhecimentos sobre esse campo de estudos na área brasileira de Educação em Ciências.
\end{abstract}

Palavras-chave: Revista científica. Formação de professores. Bibliometria. Educação em Ciências.

\begin{abstract}
Teachers' Education appears frequently in discussions in the field of Science Education. We have found several papers in events, books and journals that corroborate the breadth and relevance of this subject in the area. However, there is still a lack that could expose contributive and complementary indicators on the status of knowledge of these papers. In order to fill part of this gap, we conducted a survey that aimed to draw a scientometric profile of the articles about teacher education, published in the journal "Ciência \& Educação". From 579 articles published from 1998 to 2014, we analyzed 345 articles with keywords related to teacher education. We draw special attention to authorship indicators, production, content, and bibliography. The results expose a quantitative panorama, which expands our knowledge of this field of study in the area of Brazilian Science Education.
\end{abstract}

Keywords: Scientific journal. Teachers education. Bibliometry. Science education.

\footnotetext{
${ }^{1}$ Universidade Estadual do Sudoeste da Bahia (UESB), Departamento de Ciências Biológicas, Programa de Pós-Graduação em Educação Científica e Formação de Professores, Jequié, BA, Brasil.

E-mail:<juliorazera@yahoo.com.br>.
} 


\section{Introdução}

O interesse sobre formação de professores é crescente na área brasileira de Educação. Como consequência, há um aumento da produção científica sobre esse tema (ANDRÉ, 2010). Encontramos grande e diversificado número de trabalhos publicados em anais de eventos, livros e periódicos da área educacional geral, que corroboram a amplitude e relevância que atualmente é dada à formação docente. Esse fenômeno também ocorre na especificidade da área de Educação em Ciências, que, nas últimas três décadas, viu ampliar o interesse em suas publicações (ALMEIDA; NARDI, 2013). A formação de professores está se constituindo em um campo autônomo de pesquisa. A produção científica crescente nos ajuda a compreender esse processo de constituição da formação de professores como campo autônomo de pesquisa, tornando-se "[...] cada vez mais premente uma discussão sobre como vem se configurando esse campo de estudos” (ANDRÉ, 2010, p. 174).

Há pesquisas de estado do conhecimento sobre formação de professores na área educacional (e.g., ANDRÉ et al., 1999; BRZEZINSKI; GARRIDO, 2001) e na área de Educação em Ciências (e.g., SILVA; MEGID NETO, 2006). São pesquisas relevantes que possibilitam melhor compreensão do assunto estudado e, por consequência, da área de conhecimento afim. No entanto, outros tipos de pesquisa também podem contribuir nessa tarefa. Estamos nos referindo aos estudos de natureza quantitativa, em especial, aqueles fundamentados na cienciometria.

As pesquisas cienciométricas são de natureza quantitativa. Em conjunto com pesquisas de estado do conhecimento, as pesquisas cienciométricas contribuem no delineamento de um panorama mais completo sobre determinado assunto ou área. No Brasil, ainda há uma lacuna de estudos cienciométricos sobre formação de professores em trabalhos publicados na área de Educação em Ciências. Essas pesquisas podem expor indicadores contributivos e complementares sobre o atual estado de conhecimento. Com o intuito de preencher parte dessa lacuna (entendemos que apenas um conjunto de várias e diversificadas pesquisas conseguirá uma configuração global sobre o campo), este artigo relata uma pesquisa que teve como objetivo delinear um perfil cienciométrico dos artigos que trazem descritores sobre formação de professores publicados na revista Ciência \& Educação entre 1998 e 2014.

\section{Quadro teórico-metodológico}

Como dito anteriormente, há um interesse crescente pela formação de professores em nossa área e uma necessidade de obter mais conhecimentos sobre esse campo. Isso nos impulsiona a buscar cada vez mais dados em trabalhos publicados, com o intuito de conhecer o tema de modo mais completo. Dados que relacionam formação de professores e a área de Educação em Ciências podem ser apresentados e analisados por diferentes tipos de investigação. Juntamente com outras pesquisas, os estudos bibliométricos e cienciométricos nos ajudam a caracterizar de forma mais completa essa interface.

Bibliometria e cienciometria estão correlacionadas: "a cienciometria aplica técnicas bibliométricas à ciência” (SPINAK, 1998, p. 142). Os dados e indicadores obtidos em pesquisas cienciométricas são usados para "traçar um perfil dos campos científicos [...], de cada disciplina, a posição dos principais atores dentro do mapa e as representações específicas de 
cada um dos ramos do conhecimento" (VANTI, 2002, p. 156). Enfim, permitem demonstrar e compreender a produção de uma área de pesquisa, pois "[...] de forma geral, brindam um panorama do comportamento de um grupo de conhecimento a partir da produção científica publicada (MAZ et al., 2009, p. 186). No Brasil, são poucos os estudos cienciométricos na área de Educação em Ciências. Um deles, de Coutinho et al. (2012), foi recentemente publicado em revista internacional.

Há muitas razões para se avaliar os trabalhos científicos. No entanto, as avaliações não são automáticas; alguém deve fazê-las (GONZÁLEZ DE DIOS; MOYA; MATEOS HERNÁNDEZ, 1997, p. 235). É dentro dessa perspectiva que surge este trabalho, aqui relatado. Apesar de algumas críticas daqueles que defendem que os indicadores de teses e dissertações seriam mais significativos sobre aspectos gerais de produção de uma área científica (e.g., SANTOS et al., 2007), as revistas científicas são relevantes e também servem a esse propósito, porque elas "têm um papel formal, o de canal de comunicação, e outro talvez menos explícito mas amplamente reconhecido, como força ou poder que opera na comunidade acadêmica e profissional" (JIMÉNEZ ALEIXANDRE; GARCÍA-RODEJA GAYOSO, 1997, p. 11, tradução nossa). Além de relevante "[...] canal formal de disseminação da ciência", as revistas científicas também se constituem como "[...] fonte educacional e histórica do conhecimento produzido" (RIBEIRO, 2006, p. 6). Enfim, as revistas científicas nos ajudam a traçar um perfil das áreas e de seus respectivos conteúdos. Neste caso, por intermédio da revista Ciência \& Educação, conhecemos um pouco mais sobre os elementos que constituem a formação de professores na área de Educação em Ciências. Em parte, também respondemos às reclamações de André (2010), pois expusemos mais dados para se discutir a configuração desse campo de estudos.

\section{Procedimentos metodológicos}

Este artigo se refere a um relato de pesquisa quantitativa, na qual foram utilizados fundamentos, indicadores e técnicas adaptados de estudos bibliométricos. Foram consultados $579 \operatorname{artigos}^{2}$ da revista Ciência \& Educação, publicados entre 1998 e 2014. Ciência \& Educação foi escolhida em virtude de sua relevância, escopo e quantidade maior de artigos publicados. No momento da coleta, era a única revista brasileira avaliada pela Coordenação de Aperfeiçoamento do Pessoal de Nível Superior (Capes) no estrato A1 da área de Ensino que apresentava o escopo direcionado para o âmbito geral de Educação em Ciências e não somente para uma de suas disciplinas específicas (e.g., Ensino de Física).

Os 579 artigos (em arquivos PDF - Portable Document Format) foram transferidos do Portal SciELO para o computador do pesquisador, a fim de serem codificados e preparados para todas as etapas da pesquisa. A codificação seguiu um padrão de ordenamento já utilizado em outras pesquisas do autor. Estes são dois exemplos de códigos recebidos pelos artigos que foram objetos desta pesquisa: ce.v05.n01.a98.n01.opr (ce = Ciência \& Educação; v05 = volume

\footnotetext{
${ }^{2}$ Somente foram consultados documentos caracterizados como artigos. Os demais tipos foram desconsiderados.
} 
5; n01 = número um, o primeiro número disponível na versão eletrônica da revista; a98 = ano da edição; $n 01=1^{\circ}$ artigo do respectivo número; opr = três primeiras letras do título do artigo), ce.v20.n04.a14.n15. med (ce = Ciência \& Educação; v20 = volume 20; n04 = número 4; a14 $=$ ano da edição; $\mathrm{n} 15=15^{\circ}$ artigo do respectivo número; med $=$ três primeiras letras do título do artigo). Essa organização permitiu fácil identificação, localização e acesso no decorrer da pesquisa, por exemplo, nas diferentes necessidades de verificação ou confirmação de dados. Os aplicativos Foxit ${ }^{\circledR}$ Reader $^{\circledR}$ (versão 6.2.0.0429), Hermetic Word Frequency Counter Advanced ${ }^{\circledR}$ (versão 10.0) e Microsoft Excel ${ }^{\circledR}$ (versão 2007), Microsoft Bloco de Notas Profesional ${ }^{\circledR}$ (versão 6.1) e Microsoft Office $\operatorname{Word}^{\circledR}$ (versão 2007) foram utilizados para a busca dos descritores, organização e composição dos indicadores analisados.

Os descritores ${ }^{3}$ buscados em cada um dos 579 artigos foram: "Formação de Professor(es)" (FdeP); "Formação do(s) Professor(es)" (FdosP); "Formação Docente" (FD); "Formação Inicial" (FI); "Formação Contínua/Continuada" (FC); "Formação em Serviço" (FS); "Formación del Profesorado" (FdelP); "Formación de Profesor" (FnP); “Teacher Training” (TT); "Teacher Education" (TE); "Formation des Enseignants" (FE). Tendo o resultado da primeira busca eletrônica, todos os artigos foram revisados manual e individualmente, a fim de filtrar alguma incongruência entre os descritores detectados e os descritores desta pesquisa. Todos os artigos com presença de pelo menos um desses descritores foram separados e organizados em arquivos eletrônicos para análise.

Os resultados foram divididos em duas partes. A primeira apresenta indicadores cienciométricos do conjunto de artigos que mencionam (citam, registram) pelo menos um dos descritores (que serão chamados de FP1+). A segunda apresenta indicadores cienciométricos do conjunto de artigos com dez ou mais menções a esses descritores, referentes à formação de professores (que serão chamados de FP10+).

Para constituir o perfil almejado, em especial, trabalhamos com indicadores que contemplaram aspectos de conteúdo, de produção-autoria e de referências bibliográficas utilizadas. De acordo com Fernández Cano e Bueno Sánchez (1998), há uma diversidade de indicadores cienciométricos que podem ser usados. Entendemos que esses indicadores serviram aos propósitos deste artigo.

\section{Resultados e discussão}

Nesta primeira parte, apresentamos e discutimos indicadores cienciométricos do conjunto de artigos que mencionam pelo menos um dos descritores $(\mathrm{FP} 1+)$. Iniciamos com indicadores mais gerais e, depois, com indicadores mais específicos de conteúdo e produção.

\footnotetext{
${ }^{3}$ Descritores são termos de um vocabulário controlado (Thesaurus), que identificam conceitos de uma área de conhecimento sem ambiguidades ou equívocos de sentido. Eles ajudam na identificação de assuntos de um trabalho científico e são usados na indexação em bases de dados (FERREIRA, 1999; RIBEIRO, 2006). O conceito de descritores usado na pesquisa não se confunde com palavras-chave informadas nos artigos (i.e., nossa busca não se restringiu às palavras-chave).
} 
Dentre os 579 artigos consultados, encontramos 345 artigos FP1+ (média de aproximadamente 60\%). Os artigos FP1+ estiveram presentes em todos os anos em que a Ciência $\mho$ Educação foi editada (Tabela 1).

Tabela 1. Distribuição dos artigos consultados e analisados (FP1+)

\begin{tabular}{lccc}
\hline Ano & $\begin{array}{c}\text { Artigos publicados e } \\
\text { consultados }(\mathbf{n = 5 7 9 )}\end{array}$ & $\begin{array}{c}\text { Artigos FP1+ } \\
(\mathbf{n}=\mathbf{3 4 5})\end{array}$ & $\begin{array}{c}\text { Artigos FP1+ } \\
\mathbf{( \% )}\end{array}$ \\
\hline 1998 & 17 & 2 & 11,8 \\
1999 & 0 & 0 & 0,0 \\
2000 & 14 & 5 & 35,7 \\
2001 & 17 & 13 & 76,5 \\
2002 & 20 & 9 & 45,0 \\
2003 & 20 & 12 & 60,0 \\
2004 & 40 & 26 & 65,0 \\
2005 & 36 & 21 & 58,3 \\
2006 & 24 & 12 & 50,0 \\
2007 & 28 & 11 & 39,3 \\
2008 & 39 & 22 & 56,4 \\
2009 & 39 & 24 & 61,5 \\
2010 & 45 & 34 & 75,6 \\
2011 & 60 & 36 & 60,0 \\
2012 & 60 & 38 & 63,3 \\
2013 & 60 & 44 & 73,3 \\
2014 & 60 & 36 & 60,0 \\
\hline
\end{tabular}

Fonte: elaborada pelo autor.

Levando-se em consideração a evolução temporal entre os artigos publicados (consultados), os artigos FP1 + e a quantidade de menções no conjunto de artigos FP1+, encontramos oscilações, mas com tendência crescente na maioria dos períodos (Gráfico 1).

Gráfico 1. Evolução diacrônica dos artigos e menções aos descritores

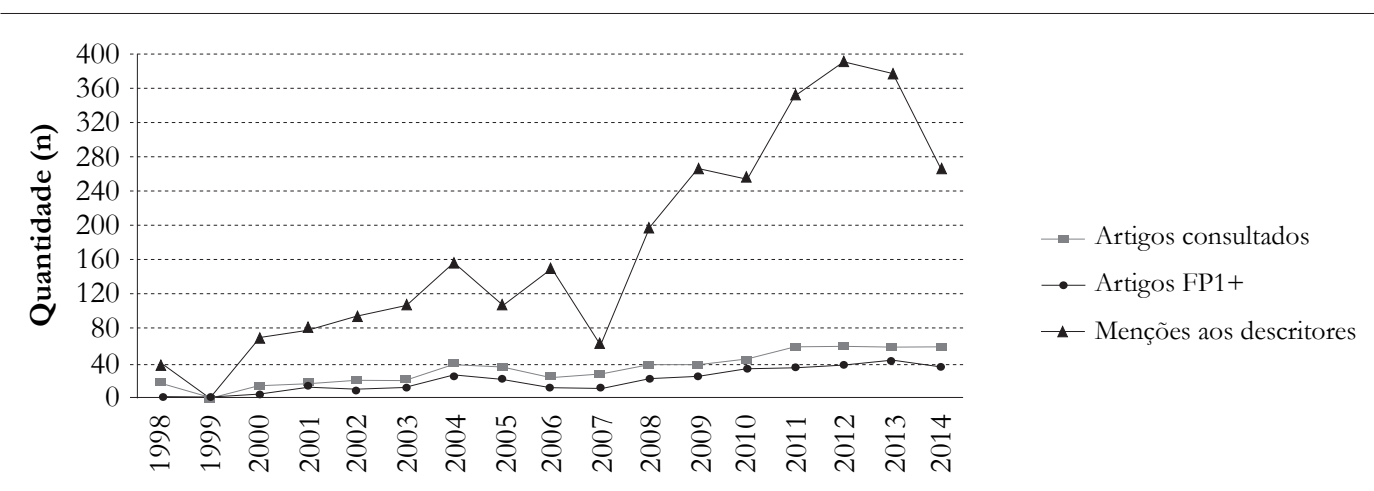

Ano de publicação

Fonte: elaborado pelo autor. 
O conjunto de 345 artigos FP1+ apresentou 2.985 menções aos descritores. O único descritor que não apareceu nos resultados de busca foi "Formation des enseignants" (em francês). O descritor que mais apareceu foi "Formação de Professor(es)" (33,8\%), seguido de "Formação Inicial" (22,3\%) e "Formação Contínua / Continuada" (18,5\%). Na Tabela 2, tem-se um panorama da distribuição quantitativa e temporal das menções a cada um dos descritores no conjunto dos artigos FP1+.

Tabela 2. Distribuição temporal de menções aos descritores nos artigos FP1+

\begin{tabular}{lrrrrrrrrrrr}
\hline Ano & FdeP & FdelP & FnP & TT & FD & FdosP & TE & FI & FC & FS & Total \\
\hline 1998 & 7 & 0 & 0 & 0 & 15 & 3 & 2 & 8 & 2 & 2 & 39 \\
1999 & 0 & 0 & 0 & 0 & 0 & 0 & 0 & 0 & 0 & 0 & 0 \\
2000 & 33 & 0 & 0 & 0 & 10 & 2 & 2 & 2 & 22 & 0 & 71 \\
2001 & 33 & 6 & 4 & 0 & 2 & 6 & 9 & 10 & 10 & 0 & 80 \\
2002 & 33 & 4 & 0 & 0 & 8 & 1 & 7 & 22 & 22 & 0 & 97 \\
2003 & 20 & 1 & 6 & 0 & 12 & 2 & 9 & 32 & 24 & 3 & 109 \\
2004 & 79 & 6 & 2 & 4 & 3 & 8 & 13 & 20 & 18 & 5 & 158 \\
2005 & 39 & 6 & 0 & 0 & 1 & 16 & 13 & 12 & 20 & 0 & 107 \\
2006 & 36 & 1 & 0 & 1 & 16 & 2 & 5 & 47 & 42 & 0 & 150 \\
2007 & 31 & 1 & 1 & 0 & 7 & 4 & 2 & 13 & 3 & 0 & 62 \\
2008 & 70 & 5 & 5 & 4 & 21 & 8 & 8 & 31 & 47 & 0 & 199 \\
2009 & 88 & 5 & 7 & 11 & 20 & 10 & 14 & 77 & 35 & 1 & 268 \\
2010 & 71 & 7 & 5 & 3 & 15 & 7 & 8 & 80 & 59 & 1 & 256 \\
2011 & 149 & 4 & 15 & 5 & 33 & 10 & 29 & 68 & 38 & 1 & 352 \\
2012 & 131 & 5 & 5 & 12 & 45 & 29 & 20 & 119 & 26 & 1 & 393 \\
2013 & 112 & 4 & 5 & 12 & 34 & 13 & 10 & 64 & 120 & 4 & 378 \\
2014 & 76 & 5 & 14 & 3 & 13 & 6 & 23 & 62 & 64 & 0 & 266 \\
Total & $\mathbf{1 . 0 0 8}$ & $\mathbf{6 0}$ & $\mathbf{6 9}$ & $\mathbf{5 5}$ & $\mathbf{2 5 5}$ & $\mathbf{1 2 7}$ & $\mathbf{1 7 4}$ & $\mathbf{6 6 7}$ & $\mathbf{5 5 2}$ & $\mathbf{1 8}$ & $\mathbf{2 . 9 8 5}$ \\
\hline
\end{tabular}

Fonte: elaborada pelo autor.

Uma das leis da cienciometria é a de Zipf. Conhecida como Lei do Mínimo Esforço, basicamente mede e ordena a quantidade das palavras em vários textos; aquelas que mais aparecem estão fortemente correlacionadas ao núcleo do assunto tratado (VANTI, 2002). Tomando-se como base a lei de Zipf, buscamos alguns indicativos nas palavras-chave informadas nos artigos da Ciência \& Educação. Dentre os 345 artigos FP1+, registramos 1.358 palavras-chave. O conjunto de nossos descritores destacou-se dentre as palavras-chave que mais apareceram, logo à frente de "Ensino de Ciências". Ressalta-se que a busca por palavras-chave não contemplou o que os artigos apresentaram em língua inglesa (keywords), para não gerar duplicidades. Palavras-chave em espanhol foram traduzidas e também estão computadas no Quadro 1.

Dentro do conjunto de palavras-chave também foram feitas buscas para detecção dos termos isolados que se referem às principais disciplinas (matérias) constituintes da área de Educação em Ciências. Os resultados foram: Ciências ( $\mathrm{n}=120)$; Matemática $(\mathrm{n}=51)$; Física ( $n=44)$; Química $(n=26)$; Biologia $(n=25)$; Saúde $(n=11)$ e Geociências $(n=2)$. 
Quadro 1. Palavras-chave que mais apareceram nos artigos FP1+

\begin{tabular}{|c|c|}
\hline Palavras-chave & $\mathrm{n}=1.358$ \\
\hline $\begin{array}{l}\text { Formação de professores (inclui todos os descritores deste trabalho, exceto aqueles de } \\
\text { língua inglesa) }\end{array}$ & 116 \\
\hline $\begin{array}{l}\text { Ensino de Ciências (inclui Educação em Ciências, Educação Científica e Enseñanza de } \\
\text { las Ciencias) }\end{array}$ & 102 \\
\hline $\begin{array}{l}\text { História e Filosofia das Ciências (inclui História das Ciências, Epistemologia das } \\
\text { Ciências e Epistemologia) }\end{array}$ & 38 \\
\hline Educação Ambiental & 32 \\
\hline Ensino de Física & 27 \\
\hline Ensino Médio & 25 \\
\hline Ensino de Química & 23 \\
\hline Ensino Fundamental & 22 \\
\hline CTS (inclui abordagem CTS, enfoque CTS, Relações CTS e CTSA) & 19 \\
\hline Concepções & 19 \\
\hline Ensino Superior & 18 \\
\hline Ensino de Matemática & 18 \\
\hline Avaliação (inclui todos os tipos que foram apresentados) & 17 \\
\hline Currículo & 16 \\
\hline Ensino de Biologia & 15 \\
\hline Educação Matemática & 15 \\
\hline Tecnologias Educacionais (inclui TIC e Tecnologia da Educação) & 14 \\
\hline Interdisciplinaridade & 12 \\
\hline Livro didático & 12 \\
\hline
\end{tabular}

Fonte: elaborado pelo autor. 
Apresentamos, a seguir, alguns indicadores de autoria e produção de artigos FP1+. Levando-se em consideração o gênero dos autores principais, encontramos preponderância do gênero feminino sobre o masculino na produção de artigos FP1+. Uma preponderância similar foi encontrada quando se levou em consideração a totalidade de colaboradores (autores + coautores). Gênero da autoria principal: masculino 138 (40\%) e feminino 207 (60\%). Gênero da totalidade de colaboradores: masculino 360 (42,7\%) e feminino 483 (57,3\%).

Sobre a composição do número de autores em cada um dos artigos FP1+, os seguintes dados merecem destaque: (i) preponderância de artigos com composição de 2 autores; (ii) publicação de artigos escritos por conjuntos excessivos de autores (7, 8, 9 e 12 autores). Detalhes da composição de autoria são apresentados na Tabela 3.

Tabela 3. Composição quantitativa de colaboradores em cada um dos artigos FP1+

\begin{tabular}{lccc}
\hline $\begin{array}{c}\text { Composição do número } \\
\text { de autores (z) }\end{array}$ & $\begin{array}{c}\text { Quantidade de } \\
\text { artigos (n) }\end{array}$ & $\begin{array}{c}\text { Porcentagem de } \\
\text { artigos (\%) }\end{array}$ & $\begin{array}{c}\text { Quantidade bruta } \\
\text { de autores (z.n) }\end{array}$ \\
\hline 1 & 51 & 14,8 & 51 \\
2 & 183 & 53,0 & 366 \\
3 & 68 & 19,7 & 204 \\
4 & 23 & 6,6 & 92 \\
5 & 8 & 2,3 & 40 \\
6 & 4 & 1,2 & 24 \\
7 & 3 & 0,9 & 21 \\
8 & 3 & 0,9 & 9 \\
9 & 1 & 0,3 & 0 \\
10 & 0 & 0,0 & 0 \\
11 & 0 & 0,0 & 12 \\
12 & 1 & 0,3 & $\mathbf{8 4 3}$ \\
Total & 345 & $\mathbf{1 0 0 , 0}$ & \\
\end{tabular}

Fonte: elaborada pelo autor.

Para que todos os autores de cada artigo sejam contados e entrem no rol de produtores, há três sistemas de contagem na cienciometria: (i) direta - apenas os autores principais são contados; (ii) completa - todos são contados (autores + coautores); (iii) ajustada - é atribuída a cada autor sua fração de colaboração (URBIZAGÁSTEGUI ALVARADO, 2009). Optou-se por trabalhar com os dois primeiros sistemas neste artigo.

$\mathrm{Na}$ contagem completa de produtores de artigos FP1+, foram evidenciados os seguintes aspectos: (i) a grande quantidade de autores (82,1\%) com a contribuição de um único artigo; (ii) o baixo número de autores (1\%) com contribuição acima de quatro artigos (Tabela 4).

$\mathrm{Na}$ sequência, apresenta-se a distribuição de produção de artigos FP1+, de acordo com a contagem direta (Tabela 5). Estes dados chamaram a atenção: (i) 88\% dos autores contribuíram com apenas um artigo; (ii) sete autores produziram três ou quatro artigos. Esses indicadores não diferem de estudos cienciométricos de outras áreas. Corrobora a lei do elitismo de Price (1963 
apud URBIZAGÁSTEGUI ALVARADO, 2009), que basicamente assim se resume: no campo científico, muitos produzem pouco e poucos produzem muito. De acordo com Price (1963, p. 37 apud URBIZAGÁSTEGUI ALVARADO, 2009, p. 70), “[...] aproximadamente 75\% daqueles que escrevem um só artigo nunca mais voltam a escrever; e que 10\% dos escritores altamente prolíficos são os que produzem aproximadamente a metade da literatura científica mundial". Levando-se em consideração apenas os dados desta pesquisa (ver Tabelas 4 e 5; Quadros 2 e 3), há indícios de que pelo menos uma parte das características apontadas por Price também se apresenta em nossa área.

Tabela 4. Distribuição de produção de artigos FP1+ (contagem completa)

\begin{tabular}{lcc}
\hline $\begin{array}{c}\text { Contribuição em número } \\
\text { de artigos FP1+ }\end{array}$ & $\begin{array}{c}\text { Quantidade de } \\
\text { autores (n) }\end{array}$ & $\begin{array}{c}\text { Quantidade de } \\
\text { autores (\%) }\end{array}$ \\
\hline 1 & 538 & 82,1 \\
2 & 76 & 11,6 \\
3 & 21 & 3,2 \\
4 & 14 & 2,1 \\
5 & 3 & 0,5 \\
6 & 2 & 0,3 \\
7 & 1 & 0,2 \\
Total & $\mathbf{6 5 5}$ & $\mathbf{1 0 0 , 0}$ \\
\hline
\end{tabular}

Fonte: baseado em Urbizagástegui Alvarado (2006) e Urbizagástegui (2008), sobre a lei de Lotka (produtividade dos autores).

Tabela 5. Distribuição de produção de artigos FP1+ (contagem direta)

\begin{tabular}{|c|c|c|c|c|c|c|c|}
\hline $\begin{array}{l}\text { Contribuição } \\
\text { em número de } \\
\text { artigos FP1+ (z) }\end{array}$ & $\begin{array}{c}\text { Quantidade } \\
\text { de autores } \\
\text { (n) }\end{array}$ & $\begin{array}{c}\text { Quantidade } \\
\text { de artigos } \\
\text { (z.n) }\end{array}$ & $\underset{z . n}{\sum}$ & $\begin{array}{c}\text { Quantidade } \\
\text { de autores } \\
\qquad(\%)\end{array}$ & $\sum_{(\% \mathrm{de}}$ & $\begin{array}{l}\text { Quantidade } \\
\text { de artigos } \\
\text { (\% de z.n) }\end{array}$ & $\begin{array}{c}\sum_{(\% \mathrm{de}} \\
\text { artigos })\end{array}$ \\
\hline 1 & 264 & 264 & 264 & 88,0 & 88,0 & 76,5 & 76,5 \\
\hline 2 & 29 & 58 & 322 & 9,6 & 97,6 & 16,8 & 93,3 \\
\hline 3 & 5 & 15 & 337 & 1,7 & 99,3 & 4,4 & 97,7 \\
\hline 4 & 2 & 8 & 345 & 0,7 & 100,0 & 2,3 & 100,0 \\
\hline Total & 300 & 345 & --- & 100,0 & --- & 100,00 & --- \\
\hline
\end{tabular}

Fonte: baseado em Urbizagástegui Alvarado (2006) e Urbizagástegui (2008), sobre a lei de Lotka (produtividade dos autores).

As maiores contribuições individuais de artigos FP1+ estão expostas a seguir, considerando-se a contagem completa (Quadro 2) e a contagem direta (Quadro 3). Ambas as listas apresentam nomes de pesquisadores atuantes e conhecidos na área de Ensino de Ciências. 
Urbizagástegui Alvarado (2009) adaptou de Price (1986) uma classificação de produtividade, que ficou assim: (i) Grandes produtores: produzem dez ou mais artigos; (ii) Produtores moderados: de cinco a nove artigos; (iii) Produtores aspirantes: de três a quatro artigos; (iv) Produtores transeuntes: de um a dois artigos. Se levar em consideração essa classificação, não houve grandes produtores neste estudo. Apareceram somente produtores moderados, aspirantes e transeuntes (que, aliás, são a maioria). No entanto, são dados de uma única revista da área. Isso leva a crer que, na área, os grandes produtores sobre formação de professores existem e não estariam fora das tabelas apresentadas.

Quadro 2. Maiores contribuições individuais de artigos FP1+ (contagem completa)

\begin{tabular}{|l|l|l|c|}
\hline \multicolumn{1}{|c|}{ Autor } & \multicolumn{1}{c|}{ Instituição } & \multicolumn{1}{c|}{ País } & Artigos (n) \\
\hline Alberto Villani & Universidade de São Paulo & Brasil & 7 \\
\hline João Félix Praia & Universidade do Porto & Portugal & 6 \\
\hline Sergio de Mello Arruda & Universidade Estadual de Londrina & Brasil & 6 \\
\hline Royman Pérez Miranda & Universidad Pedagógica Nacional & Colômbia & 5 \\
\hline Anna Maria P. de Carvalho & Universidade de São Paulo & Brasil & 5 \\
\hline Ileana María Greca & Universidad de Burgos & Espanha & 5 \\
\hline Carlos Eduardo Laburú & Universidade Estadual de Londrina & Brasil & 4 \\
\hline Rómulo Gallego Badillo & Universidad Pedagógica Nacional & Colômbia & 4 \\
\hline Roberto Nardi & Universidade Estadual Paulista & Brasil & 4 \\
\hline Maria Inês Petrucci Rosa & Universidade Estadual de Campinas & Brasil & 4 \\
\hline José André Peres Angotti & Universidade Federal de Santa Catarina & Brasil & 4 \\
\hline Flavia Rezende & Universidade Federal do Rio de Janeiro & Brasil & 4 \\
\hline Fernanda Ostermann & Universidade Federal do Rio Grande do Sul & Brasil & 4 \\
\hline Dirceu da Silva & Universidade Nove de Julho & Brasil & 4 \\
\hline Demétrio Delizoicov & Universidade Federal de Santa Catarina & Brasil & 4 \\
\hline Daniel Gil Pérez & Universitat de València & Espanha & 4 \\
\hline António Cachapuz & Universidade de Aveiro & Portugal & 4 \\
\hline Ana Luiza de Quadros & Universidade Federal de Minas Gerais & Brasil & 4 \\
\hline Irinéa de Lourdes Batista & Universidade Estadual de Londrina & Brasil & 4 \\
\hline Edenia M. Ribeiro do Amaral & Universidade Federal Rural de Pernambuco & Brasil & 4 \\
\hline
\end{tabular}

Fonte: elaborado pelo autor.

Até aqui foram trabalhados 345 artigos que apresentaram pelo menos um dos descritores $(\mathrm{FP} 1+)$. No entanto, as menções aos descritores ocorreram em quantidade variada em cada um desses artigos. Foram encontrados artigos com apenas uma menção (i.e., de um dos descritores), mas também encontrados artigos com mais de noventa menções aos descritores. A maior parte dos artigos $(62 \%)$ apresentou de uma até seis menções. De sete até nove menções 
Quadro 3. Maiores contribuições individuais de artigos FP1+ (contagem direta)

\begin{tabular}{|l|l|l|c|}
\hline \multicolumn{1}{|c|}{ Autor } & \multicolumn{1}{c|}{ Instituição } & \multicolumn{1}{c|}{ País } & Artigos (n) \\
\hline Ana Luiza de Quadros & Universidade Federal de Minas Gerais & Brasil & 4 \\
\hline Maria Inês Petrucci Rosa & Universidade Estadual de Campinas & Brasil & 4 \\
\hline Alberto Villani & Universidade de São Paulo & Brasil & 3 \\
\hline Flavia Rezende & Universidade Federal do Rio de Janeiro & Brasil & 3 \\
\hline Lenice H. de Arruda Silva & Universidade Federal da Grande Dourados & Brasil & 3 \\
\hline Rómulo Gallego Badillo & Universidad Pedagógica Nacional & Colômbia & 3 \\
\hline Sergio de Mello Arruda & Universidade Estadual de Londrina & Brasil & 3 \\
\hline
\end{tabular}

Fonte: elaborado pelo autor.

foram encontrados 34 artigos (9,9\%). De dez ou mais menções (FP10+) foram encontrados 97 artigos (28,1\%). A distribuição é apresentada no Gráfico 2.

Gráfico 2. Distribuição da quantidade de menções aos descritores no conjunto de artigos FP1+ (n=345)

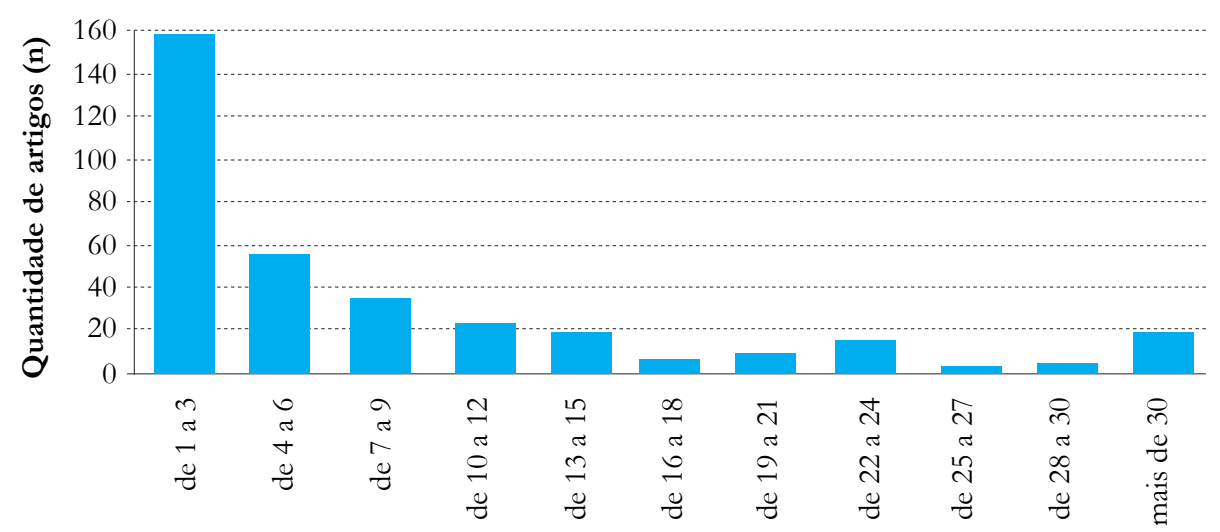

Menções aos descritores (n)

Fonte: elaborado pelo autor.

Dependendo da quantidade de descritores, cada artigo apresentou um perfil de conteúdo em relação à formação de professores.

i) Artigos com presença de até três menções aos descritores: Nessa faixa não foram encontradas abordagens centradas na formação de professores. A maioria dos descritores apareceu em menções esporádicas ou superficiais à formação de professores (e.g., menções não referenciadas; tentativas superficiais de aproximação entre o tema discutido e a formação de professores). Os descritores apareceram em títulos das obras listadas nas referências, palavras- 
chave, considerações finais, tentativas de ligação superficial e não referenciada com o tema principal abordado, etc. Como se viu, houve artigos com um dos descritores nas palavras-chave, mas ainda assim não apresentaram o foco na formação de professores.

ii) Artigos com presença de quatro a seis menções aos descritores: Não apareceram nessa faixa artigos com foco principal na formação de professores, mas, em diversos deles, a formação apareceu como foco secundário ou pano de fundo, tentando-se uma aproximação ou articulação entre as abordagens feitas e a formação de professores. Os descritores aparecem em títulos das obras referenciadas, palavras-chave, procedimentos metodológicos (e.g., coleta em cursos de formação inicial ou continuada). Em comparação com a faixa anterior, foi encontrada uma quantidade maior de artigos que apresentaram um dos descritores nas palavras-chave. Em diversos artigos, os autores destacaram que suas temáticas específicas estavam articuladas com necessidades formativas (ainda que a formação, em si, não fosse discutida).

iii) Artigos com presença de sete a nove menções aos descritores: A formação dos professores apareceu com mais destaque e frequência nessa faixa do que nas anteriores. Foram encontrados artigos com discussões voltadas especificamente sobre formação de professores e artigos com focos secundários em relação a esse tema, mas com uma articulação maior e quase sempre referenciada em suas abordagens. Alguns artigos apresentaram estudos de temáticas específicas (e.g., CTS), mas com aproximações fortes e relevantes entre essas temáticas e o processo formativo docente. Nessa faixa, os descritores já apareceram nos subtítulos dos artigos e em número maior nas palavras-chave.

iv) Artigos com presença de dez ou mais menções aos descritores: Todos os 97 artigos dessa faixa apresentaram discussões diretas e realçadas sobre formação de professores. Os descritores apareceram destacados em títulos, resumos, objetivos e listas de referências. Os temas dos artigos dessa faixa foram diversos, mas todos articulados com formação de professores (e.g., deficiências formativas na área de Ciências; legislação; formação permanente; reflexões teóricas; estudos com intervenções variadas para melhoria do processo formativo).

Em cada perfil, também se buscou a presença de outros descritores (Tabela 6).

Tabela 6. Presença de outros descritores* correlacionados ao objeto deste estudo

\begin{tabular}{lcccc}
\hline $\begin{array}{c}\text { Faixas de } \\
\text { menções aos } \\
\text { descritores }\end{array}$ & $\begin{array}{c}\text { Artigos com } \\
\text { menções à } \\
\text { "pesquisa- } \\
\text { ação" }\end{array}$ & $\begin{array}{c}\text { Artigos com } \\
\text { menções à } \\
\text { "investigação- } \\
\text { ação" }\end{array}$ & $\begin{array}{r}\text { Artigos com } \\
\text { menções a } \\
\text { "professor- } \\
\text { pesquisador" }\end{array}$ & $\begin{array}{r}\text { Artigos com } \\
\text { menções } \\
\text { a "saberes } \\
\text { docentes" }\end{array}$ \\
\hline de 1 a 3 $(\mathrm{n}=158)$ & 11 & 3 & 5 & 1 \\
de 4 a 6 $(\mathrm{n}=56)$ & 3 & 3 & 4 & 5 \\
de 7 a 9 $(\mathrm{n}=34)$ & 1 & 1 & 2 & 2 \\
10 ou mais $(\mathrm{n}=97)$ & 18 & 12 & 14 & $\mathbf{3 2}$ \\
Total $(\mathrm{n}=\mathbf{3 4 5})$ & $\mathbf{3 3}$ & $\mathbf{1 9}$ & $\mathbf{2 5}$ &
\end{tabular}

${ }^{*}$ Noções ligadas à formação de professores e que se tornaram familiares nos meios acadêmicos, segundo Almeida (2006), em virtude da ampla e crescente abordagem do tema.

Fonte: elaborada pelo autor. 
Nesta segunda parte do artigo, serão apresentados os indicadores cienciométricos do conjunto de artigos com dez ou mais menções aos descritores (FP10+). A evolução diacrônica desses artigos oscila, mas com tendência crescente no decorrer dos anos (Gráfico 3).

Gráfico 3. Evolução diacrônica dos artigos FP10+ (n=97)

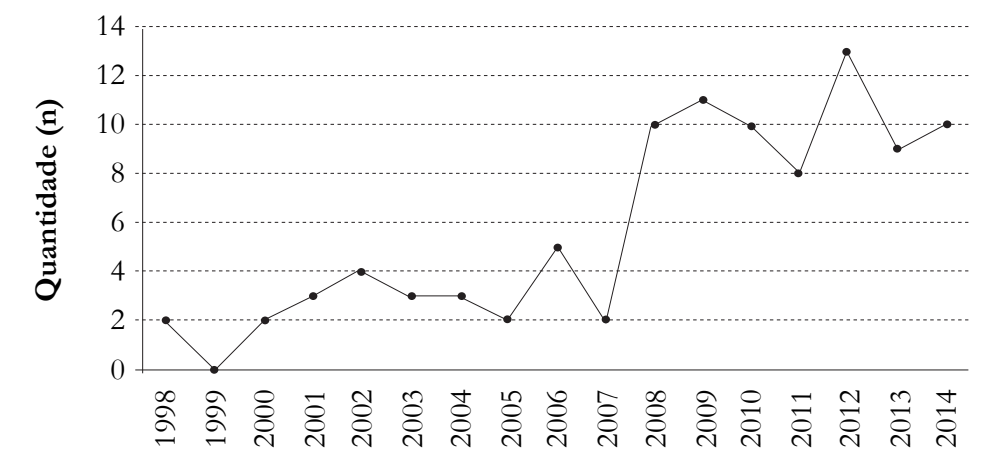

Ano

Fonte: elaborado pelo autor.

A maior parte dos artigos FP10+ referiu-se a trabalhos empíricos e práticos (88,7\%). Trabalhos teóricos e metodológicos apareceram em quantidade menor (11,3\%). A classificação de apenas dois grupos foi adaptada da tipologia de Demo (1995, p. 13), que categorizou os tipos de investigação em teórico, metodológico, empírico e prático.

Uma atenção especial foi dada às referências utilizadas pelo conjunto dos artigos FP10+. Como "[...] a função de uma referência é indicar as fontes teóricas e empíricas que dão bases aos trabalhos", como explicam Jiménez Aleixandre e García-Rodeja Gayoso (1997, p. 14, tradução nossa), os diferentes indicadores cienciométricos extraídos das listas de referências nos deram importantes pistas sobre as fontes teóricas e empíricas a envolver os trabalhos da área de Educação em Ciências sobre formação de professores.

O conjunto dos 97 artigos FP10+ apresentou um total de 2.666 referências bibliográficas (média de 27,5 referências por artigo) ${ }^{4}$. A quantidade de referências variou: foram encontrados artigos com cinco e artigos com 170 referências.

Os autores que mais apareceram nas listas de referências bibliográficas dos artigos FP10+, levando-se em consideração a autoria principal da obra, estão expostos no Quadro 4. A autoria governamental predominou (documentos curriculares e legislações são bastante citados no conjunto dos artigos). Todos os autores referenciados são bastante conhecidos e difundidos na área. A maior parte deles apresenta estudos sobre formação de professores.

\footnotetext{
${ }^{4} \mathrm{Um}$ artigo apresentou duplicidade de algumas obras na sua lista de referências bibliográficas. Nesse caso, ele foi corrigido (descartadas as obras duplicadas) para não deturpar os resultados desta pesquisa.
} 
Quadro 4. Autores principais das obras referenciadas nos artigos FP10+

\begin{tabular}{|l|c|}
\hline \multicolumn{1}{|c|}{ Autores } & Quantidade (n) \\
\hline Brasil (governo) & 92 \\
\hline Gil Pérez, D. & 34 \\
\hline Schön, D. & 34 \\
\hline Tardif, M. & 25 \\
\hline Zeichner, K. & 24 \\
\hline Porlan, R. & 24 \\
\hline Carvalho, A. M. P. & 23 \\
\hline Vigotski, L. & 22 \\
\hline Maldaner, O. A. & 22 \\
\hline Freire, P. & 20 \\
\hline Schnetzler, R. P. & 19 \\
\hline Pimenta, S. G. & 19 \\
\hline Lüdke, M. & 19 \\
\hline Cachapuz, A. & 17 \\
\hline Nóvoa, A. & 16 \\
\hline Mortimer, E. F. & 14 \\
\hline Bahktin, M. & 14 \\
\hline Hodson, D. & 14 \\
\hline Lopes, A. C. & 13 \\
\hline
\end{tabular}

Fonte: elaborado pelo autor.

As obras que mais apareceram nas referências dos artigos FP10+ nos ajudam a conhecer um pouco mais sobre as principais fontes teóricas e empíricas utilizadas nas abordagens ou linhas de pensamento dos autores que publicam trabalhos sobre formação de professores (Quadro 5). São obras conhecidas e de linhas teóricas diversas sobre o tema.

O conjunto das 2.666 referências encontradas foi composto por diferentes tipos de obras. A Tabela 7 oferece detalhes dessa distribuição, em que há prevalência dos periódicos e livros sobre os demais tipos. Esse resultado é significativo, pois demonstra a relevância do livro como fonte teórica em estudos sobre formação de professores (que será ainda maior se for somada a participação dos capítulos, que estão classificados em outro tipo). Algumas informações complementares que a Tabela 7 não traz, mas vale a pena destacar: (i) as atas dos Encontros Nacionais de Pesquisa em Educação em Ciências (ENPEC) foram mencionadas pela primeira vez em 2001; (ii) as atas do ENPEC apareceram 82 vezes nas referências (43,4\% do total de atas / anais); (iii) as atas dos Encontros Nacionais de Pesquisa em Ensino de Física (EPEF) foram mencionadas 16 vezes (8,5\% do total de atas / anais); (iv) as Reuniões da Associação Nacional 
Quadro 5. Obras que mais apareceram listadas nas referências dos artigos FP10+

\begin{tabular}{|c|c|}
\hline Obras & Quantidade (n) \\
\hline $\begin{array}{l}\text { BRASIL. Lei n. }{ }^{\circ} 9.394 / 1996 . \text { Estabelece as diretrizes e bases da educação nacional. } \\
\text { Brasília, } 23 \text { dez. } 1996 .\end{array}$ & 20 \\
\hline $\begin{array}{l}\text { CARVALHO, A. M. P.; GIL-PÉREZ, D. Formação de professores de ciências. São } \\
\text { Paulo: Cortez, 1993, 1995, } 1998 .\end{array}$ & 18 \\
\hline $\begin{array}{l}\text { SCHÖN, D. Formar professores como profissionais reflexivos. In: NÓVOA, A. } \\
\text { Os professores e sua formação. Lisboa: Dom Quixote, } 1992 \text { (e edições diversas). p. } \\
\text { 79-92. }\end{array}$ & 16 \\
\hline $\begin{array}{l}\text { TARDIF, M. Saberes docentes e formação profissional. Petrópolis: Vozes, } 2002 \text { (e } \\
\text { edições diversas). }\end{array}$ & 16 \\
\hline $\begin{array}{l}\text { LUDKE, M.; ANDRE, M. E. D. Pesquisa em educação: abordagens qualitativas. São } \\
\text { Paulo: EPU, } 1986 .\end{array}$ & 13 \\
\hline $\begin{array}{l}\text { ZEICHNER, K. A formação reflexiva de professores: ideias e práticas. Lisboa: Educa, } \\
1993 .\end{array}$ & 13 \\
\hline $\begin{array}{l}\text { BRASIL. Secretaria de Educação Média e Tecnológica. Parâmetros curriculares } \\
\text { nacionais para o ensino médio. Brasília, } 1999 .\end{array}$ & 11 \\
\hline BARDIN, L. Análise de conteúdo. Lisboa: Edições 70, 1994. & 10 \\
\hline PORLÁN, R.; RIVERO, A. El conocimiento de los profesores. Sevilla: Diada. 1998. & 10 \\
\hline $\begin{array}{l}\text { FREIRE, P. Pedagogia do oprimido. Rio de Janeiro: Paz e Terra, } 1987 \text { (e edições } \\
\text { diversas). }\end{array}$ & 9 \\
\hline NÓVOA, A. Os professores e sua formação. Lisboa: Dom Quixote, 1992. & 9 \\
\hline $\begin{array}{l}\text { BRASIL. Ministério da Educação. Secretaria de Educação Fundamental. } \\
\text { Parâmetros curriculares nacionais: ciências naturais. Brasilia, } 1998 .\end{array}$ & 8 \\
\hline $\begin{array}{l}\text { SCHNETZLER, R. P.; ARAGÃO, R. M. R. (Org.). Ensino de ciências: fundamentos } \\
\text { e abordagens. Campinas: R. Vieira, } 2000 .\end{array}$ & 8 \\
\hline $\begin{array}{l}\text { FREIRE, P. Pedagogia da autonomia. Rio de Janeiro: Paz e Terra, } 1996 \text { (e edições } \\
\text { diversas). }\end{array}$ & 7 \\
\hline $\begin{array}{l}\text { MALDANER, O. A. A formação inicial e continuada de professores de química. Ijuí: } \\
\text { Editora Unijuí, 2000, } 2003 .\end{array}$ & 7 \\
\hline
\end{tabular}


Quadro 5. continuação

\begin{tabular}{|l|c|}
\hline \multicolumn{1}{|c|}{ Obras } & Quantidade (n) \\
\hline $\begin{array}{l}\text { SHULMAN, L. S. Those who understand: knowledge growth in teaching. } \\
\text { Educational Research, Abingdon, v. 15, n. 2, p. 4-14,1986. }\end{array}$ & 7 \\
\hline VIGOTSKI, L. S. A formação social da mente. São Paulo: Martins Fontes, 2002. & 7 \\
\hline VIGOTSKI, L. S. Pensamento e linguagem. São Paulo: Martins Fontes, 2005. & 7 \\
\hline $\begin{array}{l}\text { PEREZ GÓMEZ, A. O pensamento prático do professor: a formação do } \\
\text { professor como profissional reflexivo. In: NÓVOA, A. (Org.). Os professores e sua } \\
\text { formação. Lisboa: Dom Quixote, 1992. p. 95-114. }\end{array}$ & 6 \\
\hline $\begin{array}{l}\text { BACHELARD, G. A formação do espírito científico: contribuição para uma psicanálise } \\
\text { do conhecimento. Rio de Janeiro: Contraponto, 1996. }\end{array}$ & 5 \\
\hline $\begin{array}{l}\text { BOGDAN, R. C.; BIKLEN, S. K. Investigação qualitativa em educação: uma } \\
\text { introdução à teoria e aos métodos. Porto: Porto Editora, 1994. }\end{array}$ & 5 \\
\hline $\begin{array}{l}\text { CARR, W.; KEMMIS, S. Teoria crítica de la enseñanza: investigación-acción en la } \\
\text { formación del profesorado. Barcelona: Martinez Roca, 1988. }\end{array}$ & 5 \\
\hline $\begin{array}{l}\text { IMBERNÓN, F. Formação docente e profissional: formar-se para a mudança e a } \\
\text { incerteza. São Paulo: Cortez, 2001. }\end{array}$ & 5 \\
\hline $\begin{array}{l}\text { PIMENTA, S. G. ; LIMA, M. S. L. Estágio e docência. São Paulo: Cortez, 2004, } \\
\text { 2010. }\end{array}$ & 5 \\
\hline
\end{tabular}

Fonte: elaborado pelo autor.

de Pós-graduação e Pesquisa em Educação (ANPED) foram citadas oito vezes (4,2\% do total de atas / anais); (v) o Simpósio Nacional de Ensino de Física (SNEF) apareceu seis vezes (3,2\% do total de atas / anais de eventos).

Nos títulos das referências, houve predominância da língua portuguesa ( $\mathrm{n}=1.922 \mathrm{ou}$ $72,1 \%$ ) sobre a língua estrangeira ( $\mathrm{n}=744$ ou 27,9\%). Apenas nas publicações de 2001 o número de referências com títulos em língua estrangeira sobressaiu. A partir de 2007, os títulos em português tiveram forte tendência de crescimento (Gráfico 4).

Os periódicos são relevantes ferramentas de difusão de conhecimentos científicos e, quando consolidados, se tornam referências obrigatórias nas suas respectivas áreas. Nesta pesquisa, os periódicos que mais apareceram são bastante tradicionais na área de Educação em Ciências (Quadro 6). A revista Ciência \& Educaşão, fonte desses dados, foi mencionada pela primeira vez nas referências em 2002. 
Tabela 7. Distribuição temporal dos tipos de obras de referências nos artigos FP10+

\begin{tabular}{|c|c|c|c|c|c|c|c|c|c|c|c|c|c|c|c|c|c|c|}
\hline \multirow[b]{2}{*}{ Tipo } & \multicolumn{17}{|c|}{ Ano de publicação } & \multirow[b]{2}{*}{ Total } \\
\hline & 98 & 99 & 00 & 01 & 02 & 03 & 04 & 05 & 06 & 07 & 08 & 09 & 10 & 11 & 12 & 13 & 14 & \\
\hline $\mathrm{P}$ & 2 & 0 & 3 & 111 & 32 & 21 & 51 & 16 & 14 & 21 & 76 & 78 & 58 & 88 & 93 & 95 & 107 & 866 \\
\hline $\mathrm{L}$ & 5 & 0 & 14 & 40 & 38 & 20 & 21 & 19 & 29 & 23 & 70 & 103 & 73 & 82 & 110 & 75 & 99 & 821 \\
\hline $\mathrm{C}$ & 1 & 0 & 4 & 26 & 19 & 12 & 20 & 16 & 18 & 8 & 22 & 36 & 24 & 31 & 46 & 53 & 41 & 377 \\
\hline A & 0 & 0 & 2 & 13 & 4 & 7 & 8 & 2 & 7 & 1 & 7 & 14 & 11 & 10 & 9 & 21 & 73 & 189 \\
\hline G & 1 & 0 & 0 & 0 & 2 & 0 & 6 & 4 & 3 & 0 & 28 & 7 & 19 & 33 & 18 & 15 & 17 & 153 \\
\hline $\mathrm{D}$ & 0 & 0 & 0 & 0 & 2 & 1 & 5 & 0 & 9 & 4 & 6 & 7 & 17 & 5 & 12 & 5 & 40 & 113 \\
\hline $\mathrm{T}$ & 0 & 0 & 1 & 9 & 3 & 2 & 1 & 4 & 5 & 4 & 0 & 11 & 11 & 9 & 10 & 6 & 8 & 84 \\
\hline $\mathrm{O}$ & 5 & 0 & 0 & 0 & 0 & 0 & 9 & 3 & 2 & 1 & 3 & 8 & 9 & 6 & 6 & 6 & 5 & 63 \\
\hline
\end{tabular}

Notas: P- periódicos; L- livros; C- capítulos de livros; G- documentos governamentais; A- atas e anais de eventos; T- teses de doutorado; D- dissertações de mestrado; O- outras obras diversas (e.g., filmes, trabalhos de conclusão de curso, projetos, relatórios, jornais).

Fonte: elaborada pelo autor.

Gráfico 4. Evolução diacrônica dos idiomas das referências utilizadas nos artigos FP10+

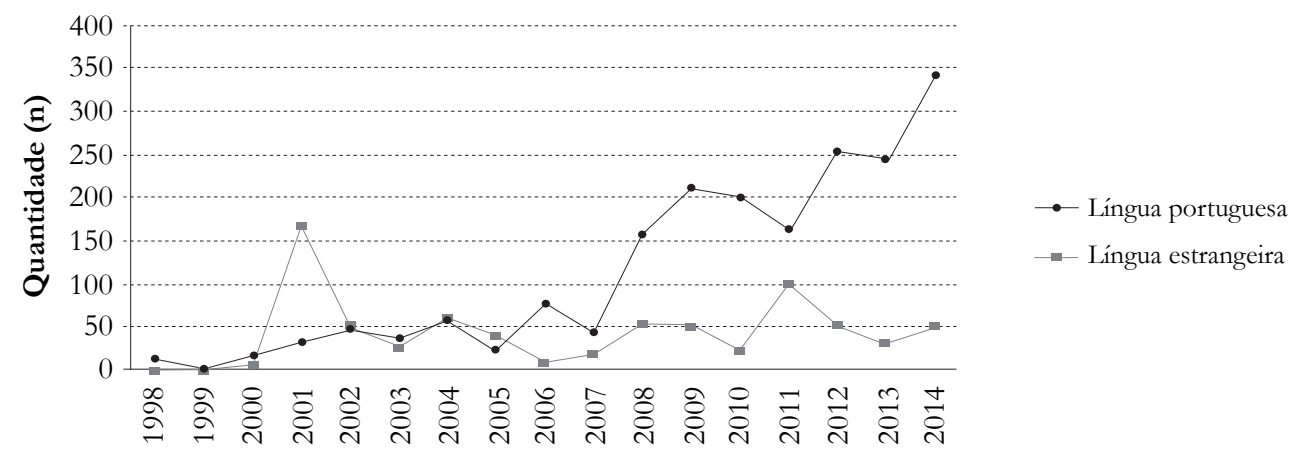

Ano

Fonte: elaborado pelo autor.

Do conjunto de 866 menções aos periódicos nas listas de referências dos artigos FP10+, encontramos uma participação equilibrada entre periódicos brasileiros $(51,5 \%)$ e estrangeiros (48,5\%). No entanto, a partir de 2011, houve um forte crescimento na participação dos periódicos brasileiros (Gráfico 5).

No conjunto de referências dos artigos FP10+, prevaleceu maior contribuição de periódicos da área de Educação em Ciências e Matemática $(58,1 \%)$ em relação aos periódicos de outras áreas (41,9\%) (Gráfico 6). 
Quadro 6. Os periódicos que mais apareceram nas referênciasos dos artigos FP10+

\begin{tabular}{|c|c|}
\hline Nome & $\mathbf{n}$ \\
\hline ENSEÑANZA DE LAS CIENCIAS. Barcelona: Universitat Autónoma de Barcelona, 1983- & 66 \\
\hline CIÊNCIA \& EDUCAÇÃO. Bauru: Universidade Estadual Paulista, 1998- & 58 \\
\hline $\begin{array}{l}\text { INTERNATIONAL JOURNAL OF SCIENCE EDUCATION. Abingdon: Routledge, } \\
\text { 1987. Título anterior: European Journal of Science Education, 1979-1987. }\end{array}$ & 53 \\
\hline SCIENCE EDUCATION. Hoboken: John Wiley, 1996- & 47 \\
\hline $\begin{array}{l}\text { INVESTIGAÇÕES EM ENSINO DE CIÊNCIAS. Porto Alegre: Universidade Federal do } \\
\text { Rio Grande do Sul, 1996- }\end{array}$ & 40 \\
\hline JOURNAL OF RESEARCH IN SCIENCE TEACHING. Hoboken: John Wiley, 1963- & 37 \\
\hline $\begin{array}{l}\text { CADERNO BRASILEIRO DE ENSINO DE FÍSICA. Florianópolis: Universidade Federal } \\
\text { de Santa Catarina, 2010-. Título anterior: Caderno Catarinense de Ensino de Fisica, 1984- } \\
2010 .\end{array}$ & 23 \\
\hline QUÍMICA NOVA. São Paulo: Sociedade Brasileira de Química, 1978- & 19 \\
\hline $\begin{array}{l}\text { ENSAIO: pesquisa em educação em ciências. Belo Horizonte: Universidade Federal de } \\
\text { Minas Gerais, 2000- }\end{array}$ & 18 \\
\hline $\begin{array}{l}\text { EDUCAÇÃO \& SOCIEDADE. Campinas: Centro de Estudos de Educação e Sociedade, } \\
\text { 1983- }\end{array}$ & 17 \\
\hline $\begin{array}{l}\text { REVISTA BRASILEIRA DE ENSINO DE FÍSICA. São Paulo: Sociedade Brasileira de } \\
\text { Física, 1979- }\end{array}$ & 16 \\
\hline $\begin{array}{l}\text { REVISTA BRASILEIRA DE PESQUISA EM EDUCAÇÃO EM CIÊNCIAS. Belo } \\
\text { Horizonte: Associação Brasileira de Pesquisa em Educação em Ciências, 2001- }\end{array}$ & 15 \\
\hline SCIENCE \& EDUCATION. Dordrecht: Springer Netherlands, 1992- & 11 \\
\hline ALAMBIQUE: didáctica de las ciencias experimentales. Barcelona: Grao, 1994- & 11 \\
\hline CADERNOS CEDES. Campinas: Centro de Estudos de Educação e Sociedade, 1980- & 11 \\
\hline QUÍMICA NOVA NA ESCOLA. São Paulo: Sociedade Brasileira de Química, 1995- & 11 \\
\hline $\begin{array}{l}\text { REVISTA ELECTRÓNICA DE ENSEÑANZA DE LAS CIENCIAS. Vigo: Universidad } \\
\text { de Vigo, 2002- }\end{array}$ & 10 \\
\hline REVISTA DE EDUCAÇÃO. Lisboa: Universidade de Lisboa, 1993-2011. & 10 \\
\hline $\begin{array}{l}\text { REVISTA BRASILEIRA DE EDUCAÇÃO. Rio de Janeiro: Associação Nacional de Pós- } \\
\text { Graduação e Pesquisa em Educação, 2001- }\end{array}$ & 10 \\
\hline
\end{tabular}

Fonte: elaborado pelo autor. 
Gráfico 5. Evolução diacrônica de periódicos brasileiros e estrangeiros nas referências de FP10+ (n=866)

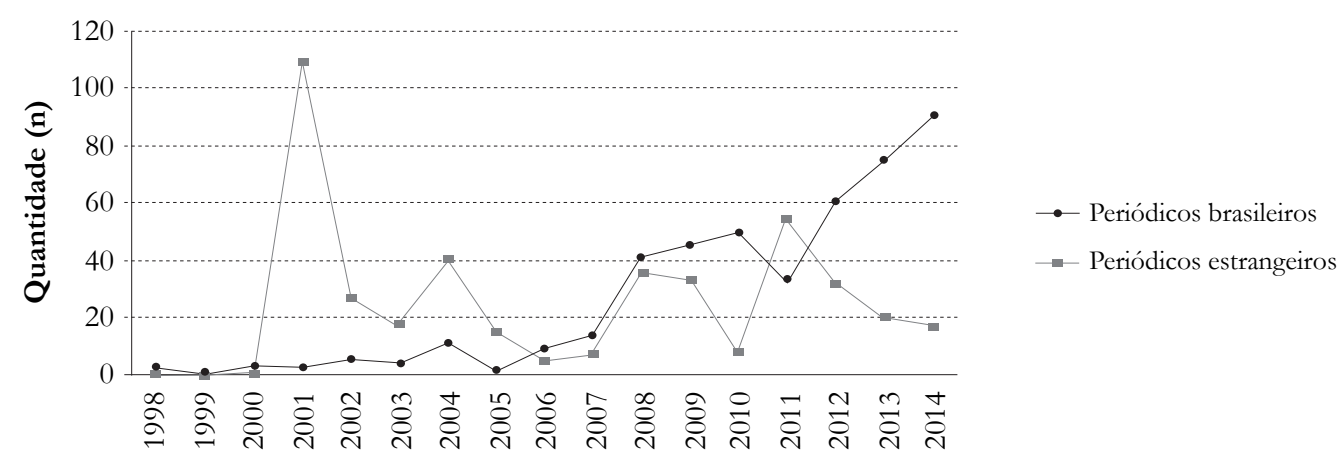

Ano

Fonte: elaborado pelo autor.

Gráfico 6. Comparação entre periódicos da área e de outras áreas nas referências dos artigos FP10+ $(\mathrm{n}=866)$

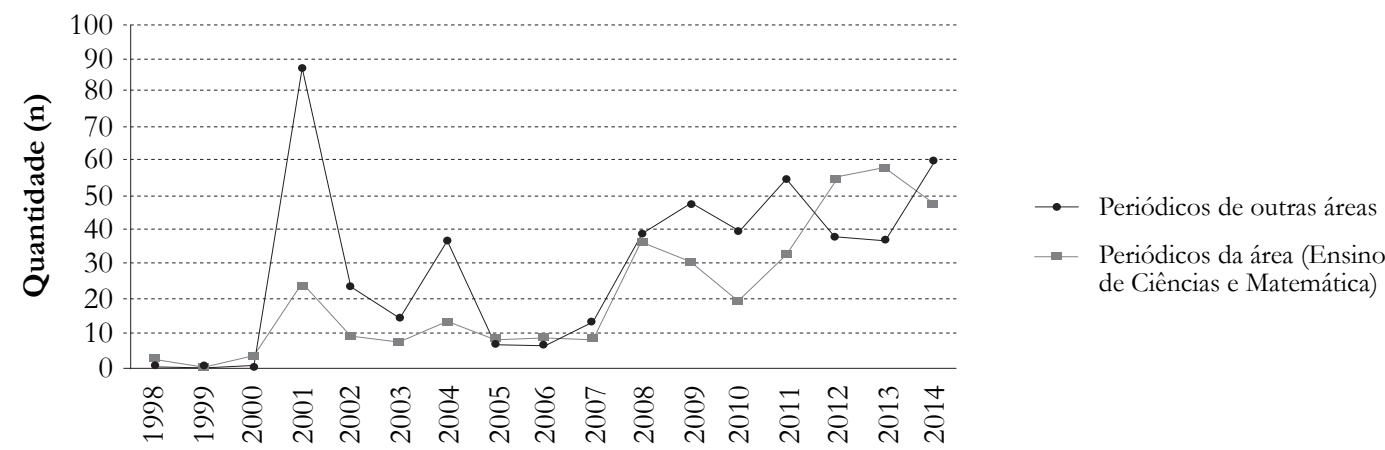

Ano

Fonte: elaborado pelo autor.

Nas listas de referências, também foram coletados dados sobre o ano de publicação das obras citadas. Assim, foi possível construir indicadores temporais comparativos entre os anos de publicação dos artigos FP10+ na revista Ciência \& Educação e a idade da literatura utilizada pelos autores.

Há diferentes métodos para se medir a obsolescência ou o envelhecimento da literatura científica. No entanto, nenhum desses métodos está isento de críticas, pois não são totalmente infalíveis ou precisos. Por depender do método, existem variações nos resultados (RUIZ BAÑOS; BAILÓN-MORENO, 1997). Neste estudo, foi apenas apresentado um cálculo sim- 
ples e comparativo entre médias ponderadas, que nos deram uma ideia de diferença temporal entre as publicações dos artigos e as referências utilizadas. Entre ambas (artigos e referências usadas), encontramos no conjunto total uma diferença média de aproximadamente dez anos.

A maior parte da literatura utilizada pelos autores de artigos FP10+ concentrou-se entre os períodos de seis a vinte anos (Tabela 8). Os resultados foram obtidos pela diferença entre os anos de publicação de cada artigo e as respectivas idades de suas referências.

Tabela 8. Tempo médio da literatura utilizada nos artigos FP10+

\begin{tabular}{lc}
\hline \multicolumn{1}{c}{$\begin{array}{c}\text { Tempo } \\
(\Delta \mathbf{t})\end{array}$} & $\begin{array}{c}\text { Quantidade de } \\
\text { obras }(\mathbf{n}=\mathbf{2 . 6 6 6})\end{array}$ \\
\hline de 0 a 5 anos & 189 \\
de 6 a 10 anos & 535 \\
de 11 a 15 anos & 789 \\
de 16 a 20 anos & 576 \\
de 21 a 25 anos & 274 \\
de 26 a 30 anos & 136 \\
de 31 a 35 anos & 59 \\
de 36 a 40 anos & 44 \\
de 41 a 45 anos & 16 \\
de 46 a 50 anos & 8 \\
Acima de 50 anos & 18 \\
Data não informada & 22 \\
\hline
\end{tabular}

Fonte: elaborada pelo autor.

\section{Considerações finais}

Esta pesquisa traçou um perfil cienciométrico da revista Ciência \& Educação. Por intermédio dela, pôde-se conhecer um pouco mais sobre alguns dos elementos que compõem essa interface entre formação de professores e Educação em Ciências.

Optou-se por apresentar uma quantidade grande de dados em tabelas e gráficos (esperamos que eles sejam úteis em consultas diversas ou pesquisas futuras) e uma parte analítica com alguns destaques específicos. Entende-se que, em muitos casos, o próprio leitor poderá fazer suas próprias inferências, notadamente aquele que está inserido na área (e.g., os maiores produtores são pesquisadores tradicionais e atuantes na área; as obras e os periódicos que mais aparecem nas referências são bastante conhecidos, etc.).

Do perfil traçado, ressaltamos estes pontos: (i) a confirmação do interesse sobre formação de professores na área - os números foram significativos e com variações quase sempre crescentes sobre o tema; (ii) os trabalhos com presença de poucas palavras referentes à formação de professores não abordaram esse tema, corroborando-se as premissas da Lei de Zipf, mas, ainda assim, apareceram neles algumas tentativas de aproximação superficial e não 
referenciadas entre o núcleo da abordagem e formação de professores; (iii) considerando-se todos os colaboradores, o gênero feminino apareceu com participação produtiva maior (58\%), mas essa proporção foi invertida na lista dos 20 que mais produziram sobre o tema (40\%); (iv) o campo de estudos sobre formação de professores na área de Educação em Ciências parece seguir uma tendência já verificada em outras diferentes áreas científicas: muitos produzem pouco e poucos produzem muito (ver Lei de Lotka); (v) trabalhos empíricos e práticos preponderam nos artigos com abordagem sobre formação de professores; (vi) ainda que não sejam consideradas referências teóricas, os documentos governamentais apareceram com relevância nas listas de referências dos artigos sobre o nosso tema; (vii) dentre os autores que mais apareceram citados nas referências, prevaleceram aqueles que não são da área de Educação em Ciências; (viii) foi relevante a participação de obras da área educacional geral entre as referências dos artigos que abordaram a formação de professores; (ix) a língua portuguesa prevaleceu na grande maioria das referências dos artigos sobre formação de professores - nos últimos anos, a tendência foi de ampliação dessa prevalência sobre as referências de língua estrangeira; (x) os livros se constituíram como importantes fontes de referências nessa interface entre formação de professores e Educação em Ciências; (xi) houve uma pequena prevalência dos periódicos da área de Educação em Ciências em relação aos periódicos de outras áreas nas referências dos artigos que abordaram a formação de professores; (xii) os periódicos brasileiros ganharam mais espaço nos últimos dez anos nas referências dos artigos sobre formação de professores.

O perfil apresentado é pontual, mas as pesquisas sobre o tema continuam sendo divulgadas. Devemos prosseguir atentos aos dados (quantitativos e qualitativos) que as pesquisas apresentam se quisermos compreender melhor a dinâmica que configura esse campo de estudos em nossa área. Estas, entre outras, são algumas das perguntas que ainda permanecem abertas (algumas já são passíveis de investigação, outras não): os indicadores da Ciência \& Educação se repetem em outros periódicos brasileiros da área? Que novidades poderiam trazer os trabalhos da área a serem publicados sobre o tema nas próximas décadas? Futuramente, haverá algum ponto de estagnação ou de saturação nesse campo?

\section{Referências}

ALMEIDA, M. J. P. M. Prescrições e recomendações ao professor na solução de problemas do ensino na educação em ciências. Ciência \& Ensino, Campinas, v. 1, n. 1, p. 47-51, 2006. Disponível em: < http://prc.ifsp.edu.br/ojs/index.php/cienciaeensino/article/view/97/97>. Acesso em: 31 maio 2016.

ALMEIDA, M. J. P. M.; NARDI, R. Relações entre pesquisa em ensino de ciências e formação de professores: algumas representações. Educação e Pesquisa, São Paulo, v. 39, n. 2, p. 335-349, abr./jun. 2013. Disponível em: <http://dx.doi.org/10.1590/S151797022013000200004>. Acesso em: 31 maio 2016.

ANDRÉ, M. Formação de professores: a constituição de um campo de estudos. Educação, Porto Alegre, v. 33, n. 3, p. 174-181, 2010. Disponível em: < http://revistaseletronicas.pucrs. br/ojs/index.php/faced/article/view/8075/5719>. Acesso em: 31 maio 2016. 
ANDRÉ, M. et al. Estado da arte da formação de professores no Brasil. Educação \& Sociedade, Campinas, v. 20, n. 68, p. 301-309, 1999. Disponível em: <http://dx.doi. org/10.1590/S0101-73301999000300015>. Acesso em: 31 maio 2016.

BRZEZINSKI, I.; GARRIDO, E. Análise dos trabalhos do GT Formação de Professores: o que revelam as pesquisas do período 1992-1998. Revista Brasileira de Educação, Rio de Janeiro, n. 18, p. 82-100, 2001. Disponível em: < http://dx.doi.org/10.1590/S1413$24782001000300008>$. Acesso em: 31 maio 2016.

COUTINHO, R. X. et al. Brazilian scientific production in science education.

Scientometrics, Budapest, v. 92, n. 3, p. 697-710, 2012.

DEMO, P. Metodologia científica em ciências sociais. 3. ed. São Paulo: Atlas, 1995.

FERNÁNDEZ CANO, A.; BUENO SÁNCHEZ, A. Síntesis de estudios bibliométricos españoles en educación: una dimensión evaluativa. Revista Española de Documentación Científica, Madrid, v. 21, n. 3, p. 269-285, 1998. Disponível em: $<$ http://dx.doi. org/10.3989/redc.1998.v21.i3.356>. Acesso em: 31 maio 2016.

FERREIRA, A. B. H. Dicionário Aurélio eletrônico: século XXI. Rio de Janeiro: Nova Fronteira, 1999. 1 CD-ROM.

GONZÁLEZ DE DIOS, J.; MOYA, M.; MATEOS HERNÁNDEZ, M. A. Indicadores bibliométricos: características y limitaciones en el análisis de la actividad científica. Anales Españoles de Pediatría, Madrid, v. 47, n. 3, p. 235-244, 1997. Disponível em: <https:// www.aeped.es/sites/default/files/anales/47-3-3.pdf>. Acesso em: 31 maio 2016.

JIMÉNEZ ALEIXANDRE, M. P.; GARCÍA-RODEJA GAYOSO, I. Hipótesis, citas, resultados: reflexiones sobre la comunicación científica en didáctica de ciencias. Enseñanza de las Ciencias, Barcelona, v. 15, n. 1, p. 11-19, 1997. Disponível em: <http://www.raco. cat/index.php/Ensenanza/article/view/21473/93468>. Acesso em: 30 maio 2016.

MAZ, A. et al. La educación matemática en la revista Enseñanza de las Ciencias: 19832006. Enseñanza de las Ciencias, Barcelona, v. 27, n. 2, p. 185-194, 2009. Disponível em: <http:/ / eprints.rclis.org/17045/>. Acesso em: 30 maio 2016.

PRICE, D. J. S. Litle science, big science... and beyond. New York: Columbia University Press, 1986.

RIBEIRO, M. P. F. A importância da indexação para a difusão do conhecimento comunicado nas revistas técnico-científicas. REME: revista mineira de enfermagem, Belo Horizonte, v. 10, n. 1, p. 6, 2006. Disponível em: < http://www.reme.org.br/artigo/detalhes/376>. Acesso em: 30 maio 2016.

RUIZ BAÑOS, R.; BAILÓN-MORENO, R. Métodos para medir experimentalmente el envejecimiento de la literatura científica. Boletín de la Asociación Andaluza de Bibliotecarios, Málaga, v. 12, n. 46, p. 57-75, 1997. Disponível em: < http:/ / eprints.rclis. org/13012/1/Ruiz_Bannos\%2C_R.pdf>. Acesso em: 31 maio 2016. 
SANTOS, R. N. M. et al. Análise cienciométrica de produção científica por meio de dissertações e teses: uma experiência brasileira. In: CONGRESSO IBEROAMERICANO DE INDICADORES DE CIÊNCIA E TECNOLOGIA, 7., 2007, São Paulo. Anais... São Paulo: CGI.BR, 2007. p. 1-10. Disponível em: <https://www.ipen.br/biblioteca/2007/ eventos/14382.pdf>. Acesso em: 31 maio 2016.

SILVA, R. C. P.; MEGID NETO, J. Formação de professores e educadores para abordagem da educação sexual na escola: o que mostram as pesquisas. Ciência \& Educação, Bauru, v. 12, n. 2, p. 185-197, 2006. Disponível em: <http://dx.doi.org/10.1590/S151673132006000200006>. Acesso em: 31 maio 2016.

SPINAK, E. Indicadores cienciométricos. Ciência da Informação, Brasília, v. 27, n. 2 , p. 141-148, 1998. Disponível em: <http://www.scielo.br/pdf/ci/v27n2/spinak.pdf>. Acesso em: 31 maio 2016.

URBIZAGÁSTEGUI, R. A produtividade dos autores sobre a Lei de Lotka. Ciência da Informação, Brasília, v. 37, n. 2, p. 87-102, 2008. Disponível em: <http://www.scielo.br/ pdf/ci/v37n2/a07v37n2.pdf>. Acesso em: 31 maio 2016.

URBIZAGÁSTEGUI ALVARADO, R. Elitismo na literatura sobre a produtividade dos autores. Ciência da Informação, Brasília, v. 38, n. 2, p. 69-79, 2009. Disponível em: $<$ http:/ / eprints.rclis.org/17758/1/Urbizagastegui-Art-v38n2-2009.pdf>. Acesso em: 31 maio 2016.

- A produtividade dos autores na literatura de enfermagem: um modelo de aplicação da lei de Lotka. Informação \& Sociedade: estudos, João Pessoa, v. 16, n. 1, p. 63-78, 2006. Disponível em: <http://www.ies.ufpb.br/ojs/index.php/ies/article/view/442/1494>. Acesso em: 31 maio 2016.

VANTI, N. A. P. Da bibliometria à webometria: uma exploração conceitual dos mecanismos utilizados para medir o registro da informação e a difusão do conhecimento. Ciência da Informação, Brasília, v. 31, n. 2, p. 152-162, 2002. Disponível em: <http://dx.doi. org/10.1590/S0100-19652002000200016>. Acesso em: 31 maio 2016. 